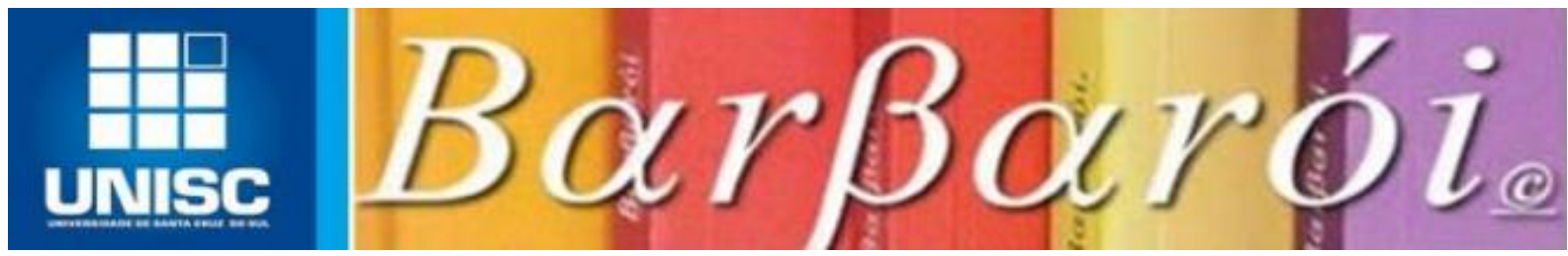

\title{
DIREITO À CIDADE: CIDADANIA E POLÍTICAS PÚBLICAS PARA HABITAÇÃO NA CIDADE DE BLUMENAU/SC
}

\author{
DOI: http://dx.doi.org/10.17058/barbaroi.v51i1.13186 \\ Cleide Gessele \\ Universidade Regional de Blumenau - FURB - Brasil.
}

Thiago Burckhart

Centro Didattico Euroamericano Sulle Politiche Costituzionali - CEDEUAM - Itália / Brasil.

\section{RESUMO}

O recente processo de desenvolvimento do capitalismo na sua forma neoliberal teve direto impacto na urbanização das cidades contemporâneas. A desorganização estrutural que esse processo causa no âmbito das cidades, donde a exclusão social é um de seus resultados, posiciona uma série de demandas sociais que podem ser compreendidos como a emergência de um "direito à cidade". Esse processo centraliza a cidade como o palco de reivindicações públicas em que as políticas por habitação emergem como uma necessidade social. A cidade de Blumenau/SC é um interessante caso para reflexão e análise. Marcada pela emergência de uma periferia invisibilizada, a cidade vive um caos histórico em suas políticas por habitação, aprofundado pelos recentes desastres socioambientais. Nesse sentido, este artigo tem por objetivo fornecer subsídios para a discussão sobre o direito à cidade tanto a partir de uma análise global quanto local, no âmbito da cidade de Blumenau/SC e da ineficácia de suas políticas públicas para a habitação. Partindo de uma abordagem sociológica, mas comprometida com a teoria do direito, tendo o pensamento de Milton Santos como marco teórico, sendo desenvolvido mediante abordagem funcionalista em chave descritiva e contextual, e privilegiando o estudo de caso da cidade de Blumenau/SC, este artigo busca evidenciar as contradições do processo de urbanização em uma das cidades mais bem posicionadas em termos de qualidade de vida, e a emergência do direito à cidade como possibilidade de emancipação.

Palavras-chave: Direito à cidade; Cidadania; Neoliberalismo; Reforma Urbana; Políticas Públicas para Habitação.

\section{Introdução}

A partir do processo de globalização em sua forma neoliberal que se desenvolveu sobretudo após a década de 1970 no mundo ocidental, e do crescente processo de urbanização e crescimento desenfreado das cidades, nasce e se fortalece a necessidade de se pensar e compreender o direito à cidade, nas suas multifacetadas dimensões. Esses macroprocessos 
desencadeiam uma série de questões que tem na cidade seu local de acontecimentos e reprodução, como as desigualdades, segregação e apartamento.

A cidade é hoje o centro pelo qual se produz e reproduz o capitalismo e o pensamento dominante $^{1}$, que dificulta estruturalmente as possibilidades de emancipação e de construção de um novo modelo democrático e participativo. A cidade se transforma na "desordem organizada", que cotidianamente é construída a partir das condições pré-estabelecidas em esferas que, salvo raras exceções, fogem ao alcance da participação do cidadão habitante da cidade e vivente dessa realidade. A falta de planejamento adequado, bem como a crescente onda de urbanização - compreendido como um processo que se desenvolve para além da materialidade - aprofunda demasiadamente a exclusão social, mesmo nas cidades com alto Índice de Desenvolvimento Humano.

Em meio ao colapso das políticas urbanas a cidadania aflora como uma possibilidade de reverter à lógica ilógica impetrada, problematizando a realidade e construindo mecanismos seja técnicos, políticos, entre outros - para a garantia do "direito à cidade". Em face disso são crescentes os movimentos sociais que reivindicam a reforma urbana, que desde 1985 marcam presença no cenário político nacional. Esses movimentos congregam a sociedade e diversas entidades públicas e privadas também engajadas nesse processo e que têm por objetivo a reforma da política urbana e a revisão do modelo de desenvolvimento, de modo a serem concebidos democraticamente de baixo para cima, e geridos a partir da governança democrática não se subjugando às forças do capital. A reivindicação desses movimentos é pela efetivação do direito à cidade, que compõe uma série de desafios e propostas que concebem como se deseja (con)viver na cidade, tendo a política de habitação como aspecto central deste direito. Nesse contexto, a cidade de Blumenau/SC pode ser tomada como um interessante caso para reflexão e análise sobre as dinâmicas do desenvolvimento, exclusão social e contradições do processo de urbanização a partir de sua periferia invisibilizada.

Nesse sentido, tomando em consideração as condições materiais das cidades contemporâneas e seus complexos processos, esse artigo objetiva fornecer subsídios teóricos e empíricos para a discussão acerca do direito à cidade a partir de uma abordagem sociológica, mas também comprometida com a teoria do direito, tomando como referência teórica o pensamento de Milton Santos, trazendo à tona questões teóricas e empíricas que problematizam o tema hodiernamente nas dimensões global e local - a partir da cidade de Blumenau/SC. O estudo se desenvolve mediante abordagem funcionalista em chave descritiva e contextual, e

\footnotetext{
${ }^{1}$ Ou mesmo "pensamento único”, como afirmava Milton Santos (2001).
} 
privilegiando o estudo de caso da cidade de Blumenau/SC. Para tanto, divide-se em três partes: I - Direito à cidade: o estado da arte em busca da emancipação; II - A cidadania urbana: exclusão social, reforma urbana e a reivindicação por uma nova cidade; e, III - Terra de ninguém: o descaso do Estado e a ausência de políticas públicas de habitação na cidade de Blumenau/SC.

\section{I - Direito à cidade: o estado da arte em busca da emancipação}

"No hay alternativas al mundo; sino alternativas en el mundo" Joaquín Herrera Flores

O processo de urbanização brasileiro ocorrido sobretudo no e a partir do século XX posicionou a cidade no centro da estrutura social. Atualmente as cidades são o espaço protagonista de um acelerado crescimento, impulsionado também pelo processo de globalização, tendo por resultado uma "urbanidade caótica" (SANTOS, 1993). Nesse contexto, entretanto, cabe posicionar a questão: o que é a cidade $?^{2}$ Numa dimensão analítica, pode-se dizer que a cidade é uma categoria ainda em construção, já que esta se edifica a partir das ações de nosso cotidiano. Contudo, historicamente essa construção se dá a partir de condições préestabelecidas, em âmbitos que, geralmente, não contam com a abertura para a participação social, como a especulação imobiliária, por exemplo.

Nesse contexto, o direito à cidade "manifesta-se como forma superior aos direitos dos direitos: direito à liberdade, à individualização na socialização, ao habitat e à habitação. $\mathrm{O}$ direito à obra (a atividade participante) e o direito à apropriação (bem distinto da propriedade" (LEFEBVRE, 2001, p. 105-119). Coloca-se como a luta pelo espaço (CARLOS, 2013, p. 2), pela busca de condições básicas de dignidade. O direito à cidade impõe a necessidade de se repensar as condições materiais pelo qual se pauta a política urbana hodierna, tanto local quanto globalmente, de modo a conceber que a cidade deve ser pensada em coletividade. Nesse sentido, pensar a cidade implica em refletir sobre o "território", mas não qualquer território, e sim aquele que é efetivamente usado. O território usado, na esteira do pensamento de Milton Santos, é aquele que soma o chão à identidade, ou seja, aquele no qual as relações humanas não apenas materiais, mas também simbólicas, elas acontecem. Para Milton Santos o território é o lugar em que se desenvolvem todas as ações sejam elas das mais variadas naturezas - política, jurídica,

\footnotetext{
${ }^{2}$ Ana Fani Carlos afirma que essa é uma pergunta que pode ficar no ar, já que "qualquer habitante da cidade sabe o que ela é, posto que ele vive na cidade e constrói no seu cotidiano o cotidiano da cidade. (CARLOS, 1991, p. 11)
}

Barbarói, Santa Cruz do Sul, n. 51, p.<54-72>, jan/jun, 2017. 
econômica, cultual, dentre outras. É este território, entendido na sua complexidade, que tomase em consideração como categoria analítica (SANTOS, 2006).

Nesse contexto, observa-se que o território da cidade contemporânea passou nas últimas décadas por um processo de alienação em prol da lógica do capital e das relações de consumo que coisificam as relações humanas ${ }^{3}$. A cidade hodierna é vista, pensada e estruturada a partir de interesses econômicos que imperam na sociedade contemporânea, interesses esses que extirpam a possibilidade de entendê-la como espaço coletivo, e o privatizam. Um dos efeitos do neoliberalismo nas cidades contemporâneas é o alargamento do espaço privado e o encolhimento do espaço público (CHAUÍ, 1992, p. 345-390) que se projeta nos centros urbanos como a materialização desse projeto político-econômico.

Nesse sentido, o direito à cidade acaba por se debilitar em virtude dessa condição, no sentido de que o acesso à cidade torna-se cada vez mais custoso, difícil e precário para os moradores das periferias das grandes cidades. Assim sendo, a cidade acaba por ser pensada e arquitetada como um espaço pelo qual o capital demostra claramente seu poderio, relegando à margem aqueles que não se assimilam com o sistema de produção imperante: os excluídos do sistema capitalista. Como resultado desse processo ocorre o aprofundamento do apartamento social nas cidades. De acordo com Milton Santos, o processo de urbanização brasileira revela uma crescente associação com a pobreza, que passou a intensificar-se com a aplicação de políticas neoliberais. $\mathrm{O}$ autor evidencia que as cidades também produzem pobreza, na medida em que esta última não é somente uma questão socioeconômica, mas também um produto espacial (SANTOS, 1993, p. 10).

A cidade vendida ao capital reproduz cotidianamente a exclusão estrutural do capitalismo, de um lado encontram-se as favelas, onde a população não possui acesso aos direitos básicos de cidadania, como saúde e educação de qualidade, onde as condições de vida e infraestrutura são precárias e a vulnerabilidade social é alta. Por outro lado vê-se as grandes e luxuosas mansões e apartamentos da classe média alta, robustos e cercados por guaritas em uma cidade apartada. É na cidade onde a exclusão social é nítida e materializada, onde o capitalismo neoliberal objetivamente se impõe como um modo de vida e uma subjetividade atroz. Há claramente neste processo a materialização da ideologia, na medida em que ela tornase a realidade material, discursiva e imaginária (Cfe. SANTOS, 2006; 1978).

\footnotetext{
3 “As catedrais, apesar de construídas pelo homem, pertencem a Deus; já as cidades de hoje, pertencem ao capital. Para usufruir da primeira é necessário a subjugação a Deus, seguir seus mandamentos. No caso da cidade é a subjugação do homem ás necessidades de reprodução do capital; onde o homem se vê capturado pelas necessidades de consumo e lazer" (CARLOS, 1991, p. 12).
} 
A urbanidade, entendida como um conjunto de relações sociais, políticas, econômicas e intersubjetivas que ocorrem no meio urbano, introjeta cotidianamente um conjunto de valores que coisificam a vida. Os valores urbanos são vistos da seguinte forma:

\begin{abstract}
As pessoas são tratadas de forma diferenciada em função de sua aparência, das roupas que vestem do carro que dirigem, lugares onde passam férias, restaurante que frequentam, cartões de crédito que usam. Até as filas de banco são diferenciadas pelo uso do cheque especial. A mídia produz um modo de vestir e de sentir dentro de determinada roupa; e até um modo de sentir out. O homem passa a ser visto, avaliado e respeitado a partir de uma aparência produzida. São ao valores urbanos. É a sociedade urbana que os impõe. (CARLOS, 1991, p. 21)
\end{abstract}

Esses valores criam uma percepção urbana que naturaliza e neutraliza a desigualdade e, portanto, nega o direito à igualdade e à liberdade de grande parte dos cidadãos da cidade. A vida mediada pelo dinheiro, marca do neoliberalismo e da monetarização das relações de consumo $^{4}$, produz o que se chama de pensamento único ${ }^{5}$, marco da globalização econômica que enxerga o desenvolvimento tão e somente a partir do viés econômico ${ }^{6}$. Dessa forma, a subjetividade urbana funciona como suporte ideológico para a política urbana e para o mantimento do status quo. Essa subjetividade é sustentada, na perspectiva de Milton Santos, pela confluência de dois fatores considerados tirânicos: o primeiro deles é a tirania do dinheiro e o segundo a tirania da informação. Ambas tiranias confluem-se no sentido de sustentar o sistema político-econômico vigente (Cfe. SANTOS, 2001; 2006)

Em efeito, apesar da Constituição Federal (CF) de 1988 garantir de forma programática em seu art. 182 que a política urbana deve proporcionar o "desenvolvimento das funções sociais da cidade e garantir o bem-estar de seus habitantes", observa-se que o crescimento desenfreado, a urbanidade caótica e a aplicação de políticas em grande medida paliativas, cria, a cada dia, um descompasso maior entre o imperativo constitucional com a realidade empírica. Outro contrassenso é a previsão constitucional do direito à moradia, previsto no art. $6^{\circ}$ da Constituição Federal, no rol dos direitos sociais que se contrapõe ao direito à propriedade (art. $5^{\circ}$, caput) que de acordo com o art. 170, inciso II, da CF deve observar ao princípio da função social da propriedade. Numa sociedade marcada pelo privilégio ao que é privado em detrimento do público, quando há colisão entre esses direitos, o direito relativizado - salvo raras exceções tende a ser o direito à moradia, mesmo se a propriedade não cumprir sua função social, prevista

\footnotetext{
${ }^{4}$ Nesse sentido, Marilena Chauí ao tratar das características do neoliberalismo, afirma que neste ocorre a passagem da economia ao monetarismo. (CHAUÍ, 2013, p. 123 - 134).

${ }^{5}$ Para aprofundamentos, ver a obra de Milton Santos (Santos, 2001).

${ }^{6}$ Em detrimento das visões contemporâneas sobre o desenvolvimento e suas dimensões para além da econômica, cfe. Amartya Sen (1999) e Ignacy Sachs (2002).
}

Barbarói, Santa Cruz do Sul, n. 51, p.<54-72>, jan/jun, 2017. 
na CF. Questiona-se, dessa forma, por que um direito social - a moradia - deve ser relativizado em detrimento do direito à propriedade - que representa a faceta da individualidade ${ }^{7}$

Com o objetivo de estabelecer parâmetros mínimos e universais para a gestão e governança das cidades, o Fórum Social das Américas juntamente com o Fórum Mundial Urbano e o V Fórum Social Mundial promulgaram em 2005 a Carta Mundial pelo Direito à Cidade $^{8}$. O documento estabelece um rol de princípios e fundamentos estratégicos do direito à cidade bem como direitos relativos ao exercício da cidadania e da participação no planejamento, produção e gestão da cidade. É definida no próprio documento como um “instrumento dirigido ao fortalecimento dos processos, reivindicações e lutas urbanas", visto que apesar de não possuir eficácia jurídica, é um importante documento para a reivindicação política ${ }^{9}$.

Nesse contexto, face às contradições inerentes às cidades nascem as reações e a busca por emancipação. Os movimentos sociais articulam-se como força política para questionar a lógica sistemática que impõe às cidades o caos urbano construído ao longo dos últimos anos e projetado ainda como a única solução ou única realidade possíveis. Eles contestam a lógica de exclusão reproduzida nas cidades, bem como as questões subjacentes como a mobilidade urbana e o acesso aos direitos básicos das populações mais carentes.

Assim,

Os movimentos sociais que exigem a reforma urbana iluminam um fato importante:
sob a égide da reprodução capitalista, a cidade se produz enquanto condição e meio
da acumulação. Nesta perspectiva ela se produz como espaços-tempo da realização
dos processos de produção, distribuição, troca, circulação de bens e mercadorias.
Como produto desta orientação a cidade também se produz sobre a égide da produção
de mercado, tornando-se, ela própria mercadoria. Assim ela fragmenta-se em lugares
apropriados apenas através do mercado imobiliário. Sob esta orientação - a da
realização do processo de acumulação - a cidade aparece ao cidadão como
exterioridade, e vivida como estranhamento redefinindo, nesta perspectiva, todas as
relações sociais, cunhando uma nova urbanidade fundada nos princípios do mercado.
(CARLOS, 2013, p. 03)

Reinventar a cidade, nesse contexto, torna-se um imperativo fundamental. Repensá-la a partir de uma perspectiva contra hegemônica é o combustível que dá vida aos movimentos

\footnotetext{
${ }^{7}$ Nesse mesmo sentido, Tarso de Melo, em abreviada síntese, afirma que a ideologia privatista ainda impera nas relações jurídicas quando o tema é "propriedade", de modo que o Estado funciona como ativo protetor da mesma. (MELO, 2009).

${ }^{8}$ A carta afirma em seu terceiro parágrafo que "as cidades estão distantes de oferecerem condições e oportunidades equitativas aos seus habitantes. A população urbana, em sua maioria, está privada ou limitada - em virtude de suas características econômicas, sociais, culturais, étnicas, de gênero e idade - de satisfazer suas necessidades básicas. Contribuem para isso as políticas públicas que, ao desconhecer os aportes dos processos de produção popular para a construção das cidades e da cidadania, violentam a vida urbana. Graves consequências resultam desse processo, como os despejos massivos, a segregação e a consequente deterioração da convivência social".

${ }^{9}$ A Carta ainda estabelece sob o prisma jusfilosófico que o direito à cidade é um novo direito humano, que potencialmente pode passar a integrar as declarações de direitos humanos no plano das Organizações Internacionais.
} 
sociais e à cidadania urbana (SANTOS, 1987). Contudo, a transposição dos interesses econômicos sobre os interesses político - diga-se, públicos e coletivos - e a relativização da soberania nacional frente ao poderio do capital, faz com que a discussão política no horizonte da emancipação das cidades torne-se extremamente dificultoso. Entende-se que a origem desse problema encontra-se em patamares mais obscuros e submersos que a discussão política, permeando em seu núcleo a configuração do sistema econômico, diga-se o capitalismo na sua forma neoliberal. Nesse sentido a busca pela emancipação abrange a busca pela criação de espaços que não se prendam ao paradigma dominante ${ }^{10}$ e a concretização/materialização dos direitos formalmente positivados no horizonte do constitucionalismo democrático dos direitos humanos, criando espaços para a reação cultural e para o nascimento de uma nova cultura política, jurídica, social e cultural.

\section{II - Cidadania e a luta por uma nova cidade, exclusão social e reforma urbana}

Partindo de uma concepção alargada de cidadania, na qual ela é entendida como um processo de alargamento de direitos ${ }^{11}$ que se evidencia tanto no plano do dever-ser - no sentido das normas jurídicas positivadas -, como no plano do ser - no sentido da concretização de direitos já conquistados -, observa-se que os movimentos sociais assumem um papel fundamental, haja vista serem eles os impulsionadores políticos da garantia formal de novos direitos e material daqueles já declarados.

Nesse sentido, pensar a cidadania no contexto urbano hodiernamente implica em pensar a luta por uma nova cidade, inclusiva e verdadeiramente democrática, que preze pela justiça ambiental, pelos direitos dos trabalhadores assalariados, pelo direito de ir e vir e pela adequada acessibilidade. A reforma urbana, nesse contexto, é uma reivindicação que ultrapassa o limite de um único movimento, tornando-se também uma pauta dos movimentos ambientais, do movimento dos sem-terra, do movimento da mobilidade urbana, dentre outros. Nasce uma interseccionalidade entre os movimentos na medida em que possuem pautas que se unem relativas à cidade. Essa característica vai ao encontro de uma percepção de cidadania mais inclusiva:

As palavras cidade, cidadão e cidadania foram, historicamente, ganhando o mesmo sentido. Podemos identificar três momentos dessa evolução. Antes de tudo, na

\footnotetext{
${ }^{10}$ Afirma Herrera Flores que "tal como propuso Michel Foucault, el pensamiento filosófico crítico lo que debe hacer es 'hacer visible lo visible' lo que está tán próximo a nosotros mismos que apenas somos capaces de precibirlo". (2005, p. 67).

${ }^{11}$ Para aprofundamentos, ver: Marshall (1964); e Melo (2004).
}

Barbarói, Santa Cruz do Sul, n. 51, p.<54-72>, jan/jun, 2017. 
antiguidade clássica, cidadania tem a ver com a condição de civitas pela qual os homens, vivendo em aglomerados urbanos, contraem relações fundadas em direitos e deveres mutuamente respeitados. Posteriormente, à condição de civitas somou-se a de polis, ou seja, o direito de os moradores das cidades participarem nos negócios públicos. Já no século XIX, a condição de cidadania é expandida com a inclusão de direitos de proteção do morador da cidade contra o arbítrio do Estado. No final do século XIX e no início do século XX, a condição de cidadão expressava também os direitos relacionados à proteção social, inicialmente relacionados aos riscos do trabalho assalariado (desemprego, acidente do trabalho etc.) e, posteriormente, estendidos à própria condição de cidadão. (RIBEIRO, 2004, p. 01)

Dessa forma entende-se que a condição de cidadão, compreendido no sentido de "habitante de uma cidade", engloba o leque de dimensões complexas da vida contemporânea, que não podem ser negligenciados no processo de formulação de políticas públicas e das decisões políticas fundamentais. Do ponto de vista da teoria crítica pode-se afirmar que a complexidade e complexificação das relações sociais é a principal característica do nosso tempo, visto que qualquer tentativa de reduzir a complexidade de uma abordagem pressupõe uma deformação de perigosas consequências ${ }^{12}$.

Nessa perspectiva, os processos reivindicativos pela democratização do espaço da cidade vocalizada pela reforma urbana tem diversos movimentos sociais que se destacam em cenário nacional, como, por exemplo, o Fórum Nacional da Reforma Urbana e o Movimento Nacional de Luta pela Moradia (MNLM). Esses movimentos trazem em suas pautas a reivindicação de espaços dignos na cidade que conta com a proposta por uma governança democrática da cidade com a participação da sociedade civil organizada ${ }^{13}$.

Nesse sentido, ao pensar o "direito à cidade", pode-se elencar pelo menos 10 itens essenciais que devem fazer parte de uma política urbana articulada: 1. Implementação do estatuto da cidade, 2. Gestão democrática e participativa, 3. Desenvolvimento urbano sustentável, 4. Habitação de qualidade para todos, 5. Saneamento ambiental para todos, 6. Prioridade do transporte público, 7. Segurança pública democrática baseada nos direitos humanos, 8. Trabalho e distribuição de renda, 9. Realização da reforma agrária, 10. Prioridade de recursos para os setores públicos.

Dessa forma, observa-se que o direito à cidade engloba uma série de fatores e estratégias que se impõe aos representantes políticos e à sociedade como desafios para pensa-los e construir ações conjuntas que sejam empiricamente possíveis. Nessa perspectiva Boaventura de Sousa

\footnotetext{
${ }^{12}$ Nesse sentido, Herrera Flores defende que "qualquier acercamiento a los derechos que simplefique o reduzca su complejidad, supone siempre una deformación de peligrosas consecuencias para los que cada día sufren las injusticias de un orden global basado en la desigualdad y en la indivisibilización de las causas profundas de su empobrecimiento". (2000, p. 19-78)

${ }^{13} \mathrm{O}$ termo governança diz respeito a uma forma (uma decisão política) para a administração da coisa pública. Nessa forma, o Poder Público se abre para a participação da sociedade civil organizada e do terceiro setor, de modo que esses novos atores sociais possam contribuir na administração pública. (GOMIDES \& SILVA, 2009).
} 
Santos ao rebater a concepção liberal de que os direitos positivados materializam-se por sua simples positivação, afirma que a concretização dos direitos no estado-providência não é um problema técnico-jurídico, mas trata-se de um problema político ${ }^{14}$. Na sua esteira de pensamento, a mobilização social também deve se projetar como uma mobilização política, exigindo tomada de postura dos representantes políticos e maior participação popular cidadã nas discussões.

Nessa linha, a reforma urbana é um conjunto de reformas estruturais, políticas e subjetivas que tem por objetivo a democratização do espaço urbano, de modo a possibilitar a inclusão da maior parte da população historicamente excluída. A reforma urbana exige a produção de uma nova subjetividade - uma subjetividade crítica - para entender a realidade e a partir dela poder intervir nas pautas reivindicatórias, entendendo-se como sujeito político e de direitos.

Como ensina Joaquín Herrera Flores, "debemos construir teorias intempestivas que irrumpanenlo real desde lo más imediato que tenemos: nuestroscuerpos, nuestras resistências, nuestra subjetividade" (2005, p. 21). Ao criticar a perspectiva do humanismo abstrato, Herrera Flores afirma que há a necessidade de construir um "humanismo concreto", ou seja "una condición humana sustentada em esa capacidade humana de hacer e deshacer mundos, de irrumpir em lo real com nuestras teorías y nuestras prácticas sociales, que nos hace ser seres humanos completos" (2005, p. 24). Hodiernamente, no contexto em que as cidades encontramse subjugadas a uma lógica neoliberal, os grupos sociais que mais encontram diretamente dificuldades no que tange ao acesso à cidade são os grupos economicamente desprovidos - os “pobres". Desse modo, a exclusão é uma importante variável para o aumento da vulnerabilidade social desses grupos, que ao não terem acesso à cidade veem seus direitos básicos serem sistematicamente violados. Nesse sentido,

\footnotetext{
O termo exclusão social é uma construção teórica que antecedeu a formulação do conceito de vulnerabilidade social, tendo, num primeiro momento, servido de referência para a caracterização de situações sociais limites, de pobreza ou marginalidade, e para a consequente formulação de políticas públicas voltadas para o enfretamento destas questões. (DIEESE, 2007, p. 10).
}

\footnotetext{
${ }^{14} \mathrm{O}$ pensador português afirma que "a falsa questão reside no pressuposto de que a especificidade operacional do direito é suficientemente 'material' para que possa questionar o direito estatal sem questionar o Estado. É evidente que essa especificidade levanta alguns problemas operacionais particulares (por exemplo, demoras e custos da justiça, brutalidade policial, congestionamento dos tribunais e das prisões, serviços de justiça insuficientes dotados de recursos financeiros e humanos, discrepância entre o direito escrito e o direito aplicado, etc.). No entanto, para além do limitado - mas importante - nível 'operacional', esses problemas não são jurídico-técnicos: são problemas políticos”. (2002, p. 161).
} 
Nessa perspectiva, a exclusão social possui relação com o fenômeno de "ruptura dos vínculos societais" ${ }^{15}$, que resulta da perda ou atrofia da solidariedade pública vinculando-se à negação (ou negligência) dos direitos sociais estabelecidos (DIEESE, 2007, p. 11). É um termo que nasce juntamente com o desmantelamento do Estado de bem-estar social, que por sua vez, criou um estado de exclusão que se caracteriza da seguinte forma:

[...] um conjunto situações marcadas pela falta de acesso a meios de vida, tais como: falta de emprego, de salários, de propriedades, de moradia, de um nível mínimo de consumo; ausência ou dificuldades no acesso a crédito, à terra, à educação, à cidadania, à bens e serviços públicos básicos. Além disso, um conjunto de questões relacionadas à identidade cultural, gênero, raça e posição na família também são elementos utilizados nas diversas caracterizações de exclusão social [...]. (DIEESE, 2007, p. 11)

Nesse sentido, a exclusão social faz parte do contexto dos centros urbanos que estruturalmente a produzem. Essa produção estrutural ainda produz uma "zona de vulnerabilidade" que congrega os setores pobres que buscam alternativas para estar incluídos ou setores médios empobrecidos que tem perdido canais de inclusão e podem potencialmente serem excluídos (DIEESE, 2007, p. 13). Essas condições produzem um profundo mal-estar para com a ordem estabelecida, e a partir do momento pelo qual os cidadãos passam a tomar consciência de sua subjetividade política e de direitos, passam a reivindicar uma outra realidade possível.

O colapso de grande parte das políticas urbanas atuais impede a garantia dos direitos socais básicos às classes mais empobrecidas, funcionando como um impulsionador dos processos de exclusão e de vulnerabilidade destes. A aplicação de medidas paliativas nas cidades representa em diversos casos a negligência perante uma série de direitos que possuem uma relação com a questão do território urbano, sobretudo os direitos sociais. Desse modo, há a necessidade de romper com as "epistemologias da cegueira", como afirma Boaventura de Sousa Santos, que implicam na construção de barreiras ideológicas que se pautam no colonialismo intelectual da visão única - a dominação de todos os gêneros: política, econômica, ideológica, cultural -, e impedem a construção de um conhecimento-emancipação, uma epistemologia da visão, capaz de reverter a lógica historicamente construída e aceita criando solidariedade. ${ }^{16}$

\footnotetext{
${ }^{15}$ Segundo Castel, "a desafiliação (exclusão) [...] representa uma ruptura de pertencimento, de vínculos societais. O desafiliado (excluído) é aquele cuja trajetória é feita de uma série de rupturas com relação a estados de equilíbrio anteriores, mais ou menos estáveis ou instáveis". (DIEESE, 2007, p. 11).

16 "Epistemologia da visão é a que pergunta pela validade de uma forma de conhecimento cujo momento e forma de ignorância é o colonialismo e cujo momento e forma de saber é a solidariedade. Enquanto, pela forma hegemônica de conhecimento, conhecemos criando ordem, a epistemologia da visão levanta a questão sobre se é possível conhecer criando solidariedade", (SOUSA SANTOS, 2002, p. 246).
} 


\section{III - Políticas públicas habitacionais na cidade de Blumenau/SC}

As políticas públicas habitacionais em países periféricos, como é o caso do Brasil, carregam consigo o signo da contradição que se inscreve no âmbito da desigualdade socioeconômica. A realidade da cidade de Blumenau/SC ilustra perfeitamente este ponto. A cidade foi fundada em 1850 por imigrantes alemães que se instalaram ao longo da bacia hidrográfica do Rio Itajaí-Açú, na região do Médio Vale do Itajaí (GUIA DE SANTA CATARINA, 2019). Trata-se de uma região marcada por um relevo de "grande complexidade geoecológica", no qual o solo e o clima não eram favoráveis às práticas agrícolas europeias trazidas pelos colonizadores. Como aponta Marco Antonio Mattedi e Maria Avila (2017, p. 190), "as formas de utilização dos recursos adotadas e o sistema de rotação primitiva de terras exigiram desmatamento e queimadas", ao passo que "a terra foi desgastada pelos cultivos sucessivos, visando garantia a subsistência" (2017, p. 190).

O seu relevo, portanto, aliado aos altos índices pluviométricos que atingem ocasionalmente a região, são responsáveis por enchentes e enxurradas na região, que fazem parte da história da cidade e da região, sendo em alguns casos em grande escala - como foram nos anos de 1983 e 1984, no qual o Rio Itajaí-Açú chegou a 15 e 16 metros respectivamente. O processo de povoamento de Blumenau está alinhado com o processo de industrialização da cidade, que durante muitos anos - e ainda hoje - se projeta como um grande polo industrial do sul do país. Marco Antonio Mattedi e Maria Avila apontam que o processo de industrialização passou por pelo menos três fases. A primeira delas ocorrida 30 anos depois da colonização, "com uma malharia e duas tecelagens, indo até o advento da eletricidade e das fábricas de fiação elétrica"; a segunda a partir do início da Primeira Guerra Mundial, no qual houve a consolidação das antigas indústrias; e a terceira entre as décadas de 1930-1940 no qual “instalaram-se fábricas de gaze farmacêutica, aço e peças de aço" (MATTEDI \& AVILA, 2017, p. 190-191) Desde então, Blumenau já passou a ser considerada metrópole regional de grande relevância econômica para a economia catarinense (MATTEDI \& AVILA, 2017; MAMIGONIAN, 1966)

Atualmente, com uma população de mais de 330.000 habitantes (IBGE, 2010), a cidade é a terceira mais populosa do Estado, possui um Índice de Desenvolvimento Humano Municipal de 0,806 (PNUD, 2013), e é considerada uma das melhores cidades para se viver no país. Entretanto, a realidade da cidade é marcada por uma flagrante contradição. Isso porque, apesar dos excelentes índices sociais, Blumenau é hoje a cidade que mais possui pessoas vivendo em favelas no Estado de Santa Catarina. De acordo com dados do IBGE de 2010 divulgados em 
2013, a cidade de Blumenau possui cerca de 22.363 pessoas vivendo em favelas, número que ultrapassa a capital do Estado Florianópolis (17.543). Somados ao número de habitantes da cidade vizinha de Gaspar (6.120 pessoas), esta região é a mais "favelizada"17 do Estado (IBGE, 2010).

A cidade que já obteve o melhor IDH do país na década de 1980 (MOSER, 2014, p. 89) tem hoje mais de $7,5 \%$ de sua população vivendo em condição de pobreza, desprovidos de serviços de energia elétrica, esgotamento sanitário, água e coleta de lixo e/ou sem titulação de propriedade do imóvel ${ }^{18}$, convivendo com uma realidade de "precarização" e "desigualdades" ou mesmo "territórios de vulnerabilidades" (AVILA et. al., 2017, p. 2). Esta realidade tornouse mais evidente a partir de 2008, quando a cidade foi atingida por um grande volume de chuvas em intensidade que provocaram enchentes, escorregamentos e resultaram em mortes, além de deixarem milhares desabrigados. Em efeito, "as chuvas intensas [...] obrigaram 14 municípios a decretar estado de calamidade pública e 63 a decretar situação de emergência, o que demonstra a extensão do desastre" (MATTEDI, 1999, p. 14), dentre elas a própria cidade de Blumenau.

A comunidade Pedro Krauss, localizada na região sul do município, foi uma das mais atingidas pela catástrofe. Trata-se de uma comunidade que pode ser tomada como exemplo de ocupação desordenada e irregular. Como demonstram Marco Antonio Mattedi e Maria Avila (2017, p. 192), a área da comunidade é "rodeada por morros e terrenos inclinados e, devido à sua localização geográfica, a localidade é considerada área de risco geológico”, o que aprofunda a dinâmica de produção de vulnerabilidades. A comunidade leva esse nome em razão da principal rua homônima que lhe dá acesso, tendo sido a ela atribuído no ano de 1961. Sua composição, como apontam Ávila e Samagaia (2013, p. 6-7) é de moradores provenientes do próprio Vale do Itajaí, assim como do planalto catarinense, Sul e Oeste de Santa Catarina, além de uma pequena parcela dos Estados do Paraná e São Paulo. No ano de 1949, por ocasião da aproximação das comemorações do centenário da cidade, a comunidade passou a receber parte dos moradores da primeira "favela" de Blumenau, a Favela Farroupilha (AVILA et. al, 2017, p. 5).

A Comunidade Pedro Krauss foi uma das comunidades mais atingidas pela catástrofe de 2008. A intensidade da tragédia "alterou a geografia socioespacial e territorial da localidade"

\footnotetext{
${ }^{17}$ Um dos clássicos que realiza uma análise sobre as favelas (slums) é o livro "Planeta Favela" de Mike Davis (2006). No livro, o autor descreve um processo crescente de favelização do mundo, e posiciona as favelas como os maiores polos de "concentração de pobreza". Esse processo se agrava, na perspectiva do autor, nos países que estão passando por processos de industrialização e urbanização acelerados.

${ }^{18}$ Tratam-se dos elementos caracterizadores do conceito de favela das Nações Unidas, que influencia a formulação. de Políticas Públicas na esfera dos seus Estados-parte (UN-HABITAT, 2006).
} 
(MATTEDI; AVILA, 2017, p. 193). A violência com que aquela tragédia deixou suas marcas na comunidade se deve em grande medida à precariedade e negligência das políticas habitacionais na cidade. Em efeito, as políticas públicas de habitação negligenciaram o fato de que grande parte da comunidade estava - e continua - vivendo em áreas de risco, propensas a novas ocasiões que podem vir a ocorrer na cidade. Essa situação não é peculiar da comunidade Pedro Krauss, mas se mostra como uma realidade de grande parte das comunidades periféricas da cidade, que além do processo de invisibilização, também contam com a negligência do Poder Público municipal.

As áreas de risco são o resultado da não execução do planejamento urbano por parte das autoridades municipais sobretudo nos anos anteriores à catástrofe. Essas áreas encontram-se em grande medida em encostas de morros típicas de cidades que possuem relevo acidentado. A falta de planejamento urbano, que inclui a não fiscalização e, em alguns casos, a concessão de alvarás para construção de casas nessas áreas contribui para que a catástrofe tenha atingido uma grande proporção (REIS \& GARROTE, 2015). A técnica política aliada a interesses econômicos, na esteira do pensamento de Milton Santos (2001), produziu seus efeitos na política habitacional urbana da cidade. Trata-se de um dos efeitos "perversos" do processo de globalização nos aglomerados urbanos (SAMAGAIA, 2010), sobretudo naqueles já marcados por relevo acidentado.

A formação do espaço urbano da cidade de Blumenau, aliado às decisões políticas, foram as duas principais causas do processo de ocupação desordenado da cidade $^{19}$, o que a deixa exposta à ocorrência de tragédias como a de 2008 (MATTEDI; AVILA, 2017, p. 191). No evento de 2008, quarenta e duas moradias foram totalmente destruídas por escorregamentos ou condenadas pela Defesa Civil (DC) (AVILA e SAMAGAIA, 2013). Após o desastre socioambiental de 2008, os problemas de habitação permanecem e de infraestrutura se agravem na localidade (MATTEDI; AVILA, 2017; AVILA et. al., 2017). Em termos teóricos, trata-se da exposição da sua população à "injustiça ambiental"20.

\footnotetext{
${ }^{19}$ Para Rúbia dos Santos (2012, p. 64), os assentamentos irregulares e de risco multiplicam-se e, ao mesmo tempo em que fazem parte das cidades, não possuem formas legais de pertencimento, como frisa a autora, e os moradores são abandonados à própria sorte.

${ }^{20}$ Esse fenômeno é tratado por Henri Acselrad (et al.) como "injustiça ambiental”. De acordo com o mesmo, "para designar esse fenômeno de imposição desproporcional dos riscos ambientais às populações menos dotadas de recursos financeiros, políticos e informacionais, tem sido consagrado o termo injustiça ambiental. Como contraponto, cunhou-se a noção de justiça ambientam para denominar um quadro de vida futuro no qual esse dimensão ambiental da injustiça social venha a ser superada. Essa noção tem sido utilizada, sobretudo, para constituir uma nova perspectiva a integrar as lutas ambientais e sociais" (p. 9). O autor entende "a noção de justiça ambiental implica, pois, o direito a um meio ambienta seguro, sadio e produtivo para todos, onde o meio ambiente é considerado em sua totalidade, incluindo suas dimensões ecológicas, físicas construídas, sociais, políticas, estéticas e econômicas". (ACSELRAD et al., 2009, p. 16).
} 
A política habitacional da cidade é historicamente marcada por sua verticalidade, que não contam com a participação da sociedade civil - o que desrespeita as determinações do Estatuto da Cidade, Lei n. 10.257/2001, que preveem a participação social na formulação de políticas públicas habitacionais (art. $2^{\circ}$, inciso II). Para além da ocupação desordenada e irregular, fruto do modelo de organização econômica e social, a tragédia de 2008 foi também gerada politicamente, seja pela incapacidade política de formular políticas e estratégias para a habitação, seja em razão do processo de formulação e gestão autoritárias de políticas públicas que exclui a participação social da sociedade organizada (MATTEDI; AVILA, 2017). Como aponta Samagaia (2010, p. 103), a prevenção a desastres é tratada na cidade de Blumenau e na região do Médio Vale do Itajaí em pontos estruturais como a "construção de barragens", não dando atenção para as questões "sociais" relacionadas a ela, que envolvem o uso e ocupação do solo.

Nesse sentido, observa-se que os aspectos de vulnerabilidade e exclusão ainda se intensificam em virtude dos riscos ambientais que essa comunidade se encontra cotidianamente submetida. Torna-se evidente, portanto, a necessidade de revisão da política urbana da cidade de Blumenau, haja vista que não são somente as comunidades periféricas que são prejudicadas - muito embora estas tenham sido as mais atingidas - por sua ineficácia, mas indiretamente toda a sua sociedade. Um novo evento climático como o de 2008 , que pode vir a ocorrer novamente, pode aprofundar significativamente a exclusão e a vulnerabilidade nessas regiões, causando ainda um maior rompimento de vínculos sociais. O objetivo das Políticas Sociais Públicas é permitir

[...] aos cidadãos acessar recursos, bens e serviços sociais necessários, sob múltiplos aspectos e dimensões da vida: social, econômico, cultural, político, ambiental entre outros. É nesse sentido que as políticas públicas devem estar voltadas para a realização de direitos, necessidades e potencialidades dos cidadãos de um Estado. (YASBEK, 2005, p. 06).

Isso implica, efetivamente, na participação da sociedade organizada na formulação de políticas públicas, como elemento constitutivo do processo de formação da cidadania. $\mathrm{Na}$ medida em que a cidadania é um processo que envolve a aquisição de direitos e a transformação do status do cidadão, como bem pontua Thomas Marshall (1964), a atuação da sociedade civil na concretização de políticas públicas - que envolvem a efetivação de direitos - é um elemento que 1) reascende o reconhecimento destes indivíduos como sujeitos políticos e como “cidadãos", e 2) são o motor para a reivindicação de novos direitos, que se plasmam no "direito à cidade". É a partir disso que torna-se possível repensar a cidadania na cidade e seu 
envolvimento com as políticas públicas, de modo que os sujeitos possam sair do seu espaço de cidadania negada para alçar a voz de "cidadãos urbanos" (SANTOS, 2006) que reivindicam seu direito à cidade.

\section{Considerações Finais}

A partir da análise feita neste artigo, à guisa de conclusão pode-se chegar a alguma conclusões que se resumem em quatro pontos centrais e que se colocam como desafios hodiernos para a política brasileira e proposições prospectivas para pensar o direito à cidade e sua relação com a cidadania.

$\mathrm{O}$ primeiro ponto propõe pensar o direito à cidade de forma integrada com outros direitos. Em efeito, o direito à cidade não pode ser integrado somente como política urbana, mas se insere num conjunto de discussões mais complexas que integram o efetivo acesso a uma série de outros direitos como saúde, educação, lazer, trabalho, que são efetivados e realizados na cidade. Assim, o direito à cidade pode ser entendido como um conjunto de meios/mecanismos que propiciam e impulsionam a inclusão social, sobretudo daqueles marginalizados pelo processo de globalização.

$\mathrm{O}$ segundo ponto propõe posicionar o direito à cidade no âmbito municipal. De fato, pensar o direito à cidade implica em articular os elementos que conformam a política urbana municipal. O município é o espaço em que a cidade se desenvolve. A cidade não se desenvolve no campo do Estado ou da União, mas na municipalidade. Para além das discussões que possam ser feitas - e são efetivamente feitas - a nível estadual ou nacional, é na dinâmica política do município que a política urbana se fará presente. É imperativo, nesse sentido, trazer os representantes públicos municipais para discussão sobre a cidade como um direito.

O terceiro ponto está intimamente atrelado ao segundo e diz respeito à necessidade de fortalecimento dos municípios, tanto política quanto economicamente. O município é o território por excelência em que a vida social se desenvolve, de modo que a sua capacidade administrativa, financeira e gestora não pode ser prejudicada, pois representaria a impossibilidade da ação política no campo loca. Para tanto, é necessária a capacitação de representantes políticos, seja no Poder Executivo quanto no Legislativo, sobre o direito à cidade.

O quarto ponto, não menos importante, é a necessidade e proposição de participação social tanto na elaboração de políticas públicas municipais para a cidade quanto na fiscalização sobre sua correta aplicação. A criação de Conselhos Municipais e a parceria com Associações 
de Moradores pode ser uma forma de fortalecer a cidadania ativa e a consciência política, podendo ainda ser canais positivos para a aproximação da sociedade civil com o Poder Público. É nesse âmbito que a cidadania se renova enquanto prática social que garante a efetivação de direitos por meio do aprimoramento de políticas públicas.

\title{
RIGHT TO THE CITY: CITIENSHIP AND PUBLIC POLICIES FOR HOUSING IN BLUMENAU/SC
}

\begin{abstract}
Abatract
The recent process of development of capitalism in its neoliberal form had a direct impact on the urbanization of contemporary cities. Structural disorganization is a process that seeks to exclude a city, and is a social exclusion of one of its members, and may be a series of social requirements that can be considered as an emergence of a "right to the city". This process centralizes the city as the stage of public hearing as housing processes emerge as a social necessity. The city of Blumenau / SC is an interesting case for reflection and analysis. Marked by the emergence of an invisible periphery, a city that lives in its housing projects, is accompanied by recent socioenvironmental disasters. In this sense, this article aims to subsidize the discussion about the right to the city both from a global and local analysis, in the space of the city of Blumenau / SC and the inefficacy of its public policies for housing. This paper seeks to highlight how the contradictions of the urbanization process in one of the most wellpositioned works in terms of quality of life, and of a sociological approach, but committed to the theory of law, with Milton Santos's thinking as a theoretical framework, developed through a functionalist approach in a descriptive and contextual key, favoring the case study of the city of Blumenau/SC, the emergence of the right to the city as a possibility of emancipation.
\end{abstract}

Key words: Right to the City; Citizenship; Neoliberalism; Urban Reform; Public Policies for Housing.

\section{Referências bibliográficas}

ACSERALD, Henri (et. al.). O que é justiça ambiental. Rio de Janeiro : Garamond, 2009.

AVILA, Maria Roseli Rossi; SAMAGAIA, Jacqueline. Reconhecimento e caracterização das áreas de concentração de pobreza em Blumenau/SC. Relatório Final de Pesquisa/FUMDES/Art. 171. Fundação Universidade Regional de Blumenau (FURB). Programa de Extensão Assessoria e Capacitação Comunitária. Blumenau, 2013. Não publicado.

AVILA, Maria Roseli Rossi; SAMAGAIA, Jacqueline; GESSELE, Cleide. Território e Desigualdade: áreas de concentração de pobreza e de risco em Blumenau. Anais do II Seminário Nacional de Serviço Social, Trabalho e Políticas Públicas. Universidade Federal de Santa Catarina, Florianópolis, 2017.

CARLOS, Ana Fani Alessandri. A Cidade. 1. ed. São Paulo: Contexto, 1991.

CHAUÍ, Marilena. Público, privado, despotismo. In: NOVAES, A. (Org.). Ética. São Paulo: Cia. das Letras, 1992.

Barbarói, Santa Cruz do Sul, n. 51, p.<54-72>, jan/jun, 2017. 
. Uma nova classe trabalhadora. In: Lula e Dilma: 10 anos de governos pósneoliberais no Brasil. Rio de Janeiro : Clacso, 2013.

DAVIS, Mike. Planeta favela. Tradução Beatriz Medina. São Paulo: Boitempo, 2006.

DIEESE, Departamento Intersindical de Estatística e Estudos Econômicos. Aspectos conceituais da vulnerabilidade social. Projeto de qualificação social para atuação de sujeitos ou grupos sociais na negociação coletiva e na gestão de Políticas públicas. 2007

GOMIDES, José Eduardo \& SILVA, Andrea Candida. O surgimento da expressão "governance", governança e governança ambiental. Revista de Ciências Gerenciais, Vol. XIII, n ${ }^{\circ} 18$, ano 2009.

GUIA DE SANTA CATARINA. Localização/Geografia/Blumenau. 2019.

HERRERA FLORES, Joaquín. Derechos Humanos como processos culturares. Crítica del humanismo abstracto. Madrid : Catarata, 2005.

Hacia una visión compleja de los derechos humanos. In: HERRERA FLORES, Joaquín. El vuelo de Anteo. Derechos humanos y crítica de la razón liberal. Bilbao: Desclée de Brouwer, S.A., 2000.

IBGE, Instituo Brasileiro de Geografia e Estatística. Coordenação de População e Indicadores Sociais. 2010

LEFEBVRE, Henri. O Direito à cidade. Tradução de Rubens Eduardo Frias. São Paulo : Editora Centauro, 2001.

MAMIGONIAN, A. Estudo geográfico das indústrias de Blumenau. Revista Brasileira de Geografia, ano XXVII(3), p. 389-481, 1966.

MARSHALL, Thomas Humphrey. Class, citizenship and social development. University of Chicago Press : Chicago, 1964.

MATTEDI, Marcos Antônio. As enchentes como tragédias anunciadas: impacto da problemática ambiental nas situações de emergência em Santa Catarina. Tese de Doutorado em Ciências Sociais. Instituto de Filosofia e Ciências Humanas da Universidade Estadual de Campinas, Campinas, 1999. 284 p.

MATTEDI, Marcos Antonio; AVILA, Maria Roseli Rossi. Desastre e território: a produção da vulnerabilidade a desastres na cidade de Blumenau/SC. Revista Brasileira de Gestão Urbana, maio/ago, 9(2), 187-202, 2017.

MELO, Milena Petters. Cidadania no Brasil: da concretização dos direitos fundamentais à construção cultural dos direitos humanos. Tese de Doutorado em Direito. Università Degli Studi di Lecce, Itália, 2004.

MELO, Tarso de. Direito e Ideologia: um estudo a partir da função social da propriedade rural. São Paulo : Expressão Popular, 2009. 
MOSER, Magali. Os contrastes de Blumenau. Jornal Expressão Universitária. Publicação do Sinsepes. Blumenau, ano IV, número 43, maio de 2014.

PNUD, Programa das Nações Unidas para o Desenvolvimento. Atlas do Desenvolvimento Humano 2013. Disponível em: http://www.pnud.org.br/arquivos/fs1-idhm-brasil.pdf

REIS, Nicollás Voss; GARROTE, Martin Stabel. Memórias da ocupação na comunidade Rua Araranguá de Blumenau/SC e sua relação com o desastre socioambiental ocorrido em 2008.

Anais do XXVIII Simpósio Nacional de Históri $a$. Lugares dos historiadores: velhos e novos desafios. Universidade Federal de Santa Catarina. Florianópolis, 2015.

SACHS, Ignacy. Caminhos para o Desenvolvimento Sustentável. Rio de Janeiro: Garamond, 2002.

SAMAGAIA, Jacqueline. Globalização e Cidade: Reconfigurações dos espaços de pobreza em Blumenau/SC. Tese de Doutorado em Geografia. Centro de Filosofia e Ciências Humanas. Programa de Pós-Graduação em Geografia. Universidade Federal de Santa Catarina. Florianópolis, 2010.

SANTOS, Milton. Por uma outra globalização: do pensamento único à consciência universal. Editora Record: Rio de Janeiro, 2001.

SANTOS, Milton. A urbanização brasileira. São Paulo : Editora Hucitec, 1993.

SANTOS, Milton (Org.). Território, territórios: ensaios sobre o ordenamento territorial. Rio de Janeiro : DP\&A, 2006.

SANTOS, Milton. O espaço dividido. Rio de Janeiro : Livraria Ed. Francisco Alves, 1978.

SANTOS, Milton. O espaço do cidadão. São Paulo : Nobel, 1987.

SANTOS, Rúbia dos. Gestão de desastres e Política de Assistência Social: estudo de caso de Blumenau/SC. Tese de Doutorado em Sociologia Política. Centro de Filosofia e Ciências Humanas. Programa de Pós-Graduação em Sociologia Política. Universidade Federal de Santa Catarina. Florianópolis, 2012, 233 p.

SEN, Amartya. Development as freedom. New York : Oxford University Press, 1999.

SOUSA SANTOS, Boaventura de. Crítica da razão indolente: contra o desperdício da experiência. $4^{a}$ ed. São Paulo : Editora Cortez, 2002.

UN-HABITAT. State of the world's cities 2006/7. London, Earthscan, 2006.

YASBEK, Maria Carmelita. Estado e Políticas Sociais. Revista Praia Vermelha. 18. ed. UFRJ. Rio de Janeiro, 2005. 


\section{Sobre os autores}

Cleide Gessele é doutora e mestre em Serviço Social pela Universidade Federal de Santa Catarina, UFSC. Professora Titular do Departamento de Serviço Social da Universidade Regional de Blumenau, FURB. Integrante do Núcleo de Estudos e Pesquisas Estado, Sociedade Civil, Políticas Públicas e Serviço Social da UFSC.

Endereço eletrônico: cleidege@yahoo.com.br

Thiago Rafael Buckhart é mestre em Direito pela Universidade Federal de Santa Catarina, UFSC. Pesquisador do Centro Didattico Euroamericano Sulle Politiche Costituzionali (Cedeuam, Itália). Pesquisador do Grupo de Estudos em Constitucionalismo Político (GConst, UFSC). Pesquisador do Núcleo de Estudos em Constitucionalismo, Internacionalização e Cooperação (Constinter, Furb). Pesquisador colaborador da Academia Brasileira de Direito Constitucional, ABDConst. Membro da Réseau ALEC “Amérique Latine, Afrique, Europe et Caraïbe" sobre "Terrotoires, populations vulnérables et politiques publiques», vinculada à Université de Limoges, França. Endereço eletrônico: thiago.burckhart@outlook.com 